\title{
Linking Climate Variables to Large-Scale Spatial Pattern and Risk of Citrus Huanglongbing: A Hierarchical Bayesian Modeling Approach
}

\author{
Kaique S. Alves, ${ }^{1}$ Lisa A. Rothmann, ${ }^{2}$ and Emerson M. Del Ponte ${ }^{1, \dagger}$ \\ ${ }^{1}$ Departamento de Fitopatologia, Universidade Federal de Viçosa, Viçosa, MG 36570-900, Brazil \\ ${ }^{2}$ Department of Plant Sciences, University of the Free State, Free State, Bloemfontein, 9300, South Africa \\ Accepted for publication 26 July 2021.
}

ABSTRACT

\begin{abstract}
Huanglongbing (HLB) is one of the most important diseases affecting citriculture in the world. Knowledge of climatic factors linked to HLB risk at large spatial scales is limited. We gathered HLB presence and absence data from official surveys conducted in the state of Minas Gerais, Brazil, over 13 years. The total count of orange and mandarin orchards, and mean orchard area, normalized to a spatial grid of 60 cells $(55 \times 55 \mathrm{~km})$, were derived from the same database. Monthly climate normals (1984 to 2013) of rainfall, mean temperature, and wind speed split into rainy (September to April) and dry (May to August) seasons (annual summary was retained) were obtained for each grid cell. Two hierarchical Bayesian modeling approaches were evaluated, both based on the integrated nested Laplace approximation method. The first, the climate covariates model (CC model), used orchard, climate, and the
\end{abstract}

spatial effect as covariates. The second, principal components (PC model), used the first three components from a principal component analysis of all variables and the spatial effect as covariates. Both models showed an inverse relationship between posterior prevalence and grid cell mean temperature during the dry season. Annual wind speed, as well as annual and rainy season rainfall, contributed to HLB risk in the CC and PC models, respectively. A partial influence of neighboring regions on HLB risk was observed. The results should assist policymakers in defining regions at HLB risk and guide monitoring strategies to mitigate further spread of HLB in the state of Minas Gerais.

Keywords: bacterial pathogens, climate change, epidemiology, modeling
Huanglongbing (HLB), also called citrus greening, is one of the most destructive citrus diseases worldwide, including in Brazil (Bassanezi et al. 2020; Gottwald et al. 2010). In Brazil, HLB was first reported in São Paulo (SP) state during the 2004 season (Coletta-Filho et al. 2004; do Carmo Teixeira et al. 2005). Thirteen years later, the incidence of HLB in sweet orange orchards in the citrus belt (spanning SP and Minas Gerais [MG] states) had increased to about 19\%, with an estimated 37 million trees infected (Fundecitrus 2019). In 2018, >57\% of orchards, including mandarins and sweet oranges in MG, were affected by HLB (Alves et al. 2020). A recent 10-year analysis showed that the epidemic front of HLB was advancing at $25.7 \mathrm{~km}$ per year in central and southern MG and advancing at as much as $45.9 \mathrm{~km}$ per year in the border region of SP (Alves et al. 2020).

Three gram-negative bacterium species of the genus 'Candidatus Liberibacter' can cause HLB: 'Ca. L. africanus' (Jagoueix et al. 1994), 'Ca. L. americanus' (Coletta-Filho et al. 2004; do Carmo Teixeira et al. 2005), and ' $C a$. L. asiaticus' (Jagoueix et al. 1994). The predominant species in Brazil was ' $\mathrm{Ca}$. L. americanus', until 2008 when a shift in the population occurred and ' $\mathrm{Ca}$. L. asiaticus'became the most prevalent species $(>99.9 \%)$ found in orchards (Bassanezi et al. 2020; Lopes et al. 2009). The bacteria exhibit persistent propagative transmission with the phloem-probing psyllid

${ }^{\dagger}$ Corresponding author: E. M. Del Ponte; delponte@ufv.br

K. S. Alves and L. A. Rothmann contributed equally to this study.

Funding: K. S. Alves thanks the Coordenação de Aperfeiçoamento de Pessoal de Nível Superior for providing a graduate scholarship (grant number 01). E. M. Del Ponte thanks the Conselho Nacional de Desenvolvimento Científico e Tecnológico for providing a research fellowship. Climate data were obtained from the NASA Langley Research Center POWER Project funded through the NASA Earth Science Directorate Applied Science Program.

The author(s) declare no conflict of interest.

(C) 2022 The American Phytopathological Society vectors, both with the nymphs and adults, which are mainly responsible for spread and transmission of the bacteria under natural conditions (Ammar et al. 2016).

The Asian citrus psyllid, Diaphorina citri, is the primary vector responsible for the spread and transmission of ' $\mathrm{Ca}$. L. americanus' and 'Ca. L. asiaticus' (Bové 2006; do Carmo Teixeira et al. 2005). The whole psyllid life cycle, including egg, nymph, and adult, encompassing pathogen acquisition, replication, transmission, survival, and spread, should be considered as factors affecting the onset and spread of HLB (Razi et al. 2014; Teck et al. 2011). Development of epidemic intervention strategies and their successful implementation is therefore reliant on determining factors driving disease development in the plant and spread between plants (Madden et al. 2007).

The prevalence of HLB in different states in Brazil can be attributed to the psyllid vectors' capability for short- (plant-to-plant and within orchard; 5 to $320 \mathrm{~m}$ ) and long-distance (between orchard; about $2.5 \mathrm{~km}$ ) movement via passive and active means: wind-assisted dispersal and consecutive short flights, respectively (Antolinez et al. 2021; Carmo-Sousa et al. 2020). Additionally, the use of infected propagative material for grafting has been demonstrated to transmit HLB and can thus contribute to dissemination of the pathogen (Van Vuuren and Da Graça 1993). Orchard-level studies indicate that clustering of HLB-infected trees occurs as a result of vector movement, with an edge effect due to trees becoming infected along an orchard border, which can subsequently lead to nearby trees becoming infected and enlarging the initial foci or generating new foci within the orchard (Bassanezi et al. 2005). At a regional level, an aggregated spatial pattern of HLB was observed in orchards in MG, with a more pronounced aggregation in mandarin (Citrus reticulata Blanco) orchards compared with sweet orange (C. sinensis Osbeck) orchards (Alves et al. 2020).

Because of HLB's polyetic nature, quantitative epidemiological studies can be difficult to implement: Multiseason data are needed, and eradication of symptomatic plants reduces the opportunity to continuously monitor disease progress (Gottwald 2010). Where 
multiyear field studies are conducted, numerous environmental factors may be associated with the spatial and temporal progress of HLB. Rainfall was positively correlated with HLB incidence in Florida, indicating that higher rainfall is associated with a greater risk of HLB infection, probably because of a plant physiological response or effects on vector population dynamics (Shimwela et al. 2018). The psyllid vector of the HLB bacterium has a narrower temperature range tolerance than that of the bacterium itself (Gutierrez and Ponti 2013). Furthermore, within the species complex, ' $C a$. L. asiaticus' tolerates higher temperatures than ' $C a$. L. americanus', which is assumed to be part of the reason for the shift in species dominance (Gasparoto et al. 2012; Lopes et al. 2009). The host as an environment also needs to be considered. For example, newly emerging leaves (flushes) have been associated with higher densities of the psyllid vector in citrus orchards (Gutierrez and Ponti 2013; Lewis-Rosenblum et al. 2015).

HLB mitigation is limited to preventive measures and includes eradication and exclusion strategies, quarantine, certified-healthy nursery trees, and insecticide applications to suppress vector populations and bacterial dissemination (Bassanezi et al. 2020; Bové 2006). Eradication of symptomatic trees aims to reduce inoculum reservoirs in order to mitigate losses and the spread of HLB, which comes at a high cost to growers (Lopes et al. 2008). In response to the HLB epidemic in Brazil, statewide initiatives were implemented in 2004 to monitor the occurrence of HLB and enforce orchard clearing when the incidence of HLB exceeded 28\% (Bassanezi et al. 2020; Craig et al. 2018). Ultimately, a regional disease management approach is the most appropriate tool for effective HLB management, which must include systematic and coordinated vector control and removal of inoculum sources (symptomatic citrus trees) from commercial and noncommercial properties (Bassanezi et al. 2013).

MG ranks third in citrus production in Brazil (Instituto Brasileiro de Geografia e Estatística 2018, cited in Carvalho et al. 2019) and is in one of the four major citrus producing regions of the country (Passos et al. 2018). We hypothesize that climatic variables (temperature, rainfall, and wind speed) and orchard-related variables, such as orchard size and citrus species, in part explain the relative geographic prevalence of HLB in MG. In this study, we aimed to link climatic factors to the present spatial distribution of HLB prevalence in MG by using hierarchical Bayesian spatial modeling. Bayesian spatial modeling should enable quantification and visualization of the disease spatial distribution, including the effect of a range of covariates and random spatial effects. The method is similar to that of a recent study that modeled the effect of climatic variables on the spatial distribution of Xylella fastidiosa in regions of Spain and Italy (Cendoya et al. 2020). The results could be used to assist policymakers, plant health extension specialists, and producers in monitoring HLB and, if needed, optimizing management strategies to specific areas based on the probability of HLB prevalence.

\section{MATERIALS AND METHODS}

HLB prevalence. The status of HLB (presence or absence) in citrus orchards has been regularly monitored by the Instituto Mineiro de Agropecuaria (Belo Horizonte, MG) in MG since the first detection of the disease in 2005. Instituto Mineiro de Agropecuaria surveys all citrus orchards across municipalities and categorizes risk for HLB. A risk 1 category is associated with municipalities where HLB has already been detected in any citrus orchard. Neighboring municipalities where HLB has not yet been detected are a risk 2 category. All citrus orchards located in the municipalities under risks 1 and 2 are monitored; if risk categories are not attributed to municipalities, the orchards within those municipalities are not monitored. Each citrus plant in all orchards is inspected for HLB and HLBlike symptoms by trained inspectors. Once an HLB-symptomatic plant is detected, samples are sent to a laboratory for confirmation by PCR assays. In this study, an orchard was categorized as HLB-present (positive) if HLB was detected between 2005 and 2018; otherwise, the orchard was classified as HLB-absent (negative).

All positive and negative (HLB-present or absent) orchards are included in the database with their respective location (latitude and longitude) and other attributes related to the orchard (citrus species, orchard area, HLB cumulative incidence, number of trees eradicated, total number of trees). A full description of the data is available elsewhere (Alves et al. 2020) and is available in a citable research compendium (osf.io/23ghm). Data were compiled into a spatial grid of $0.5 \times 0.5$ decimal degrees (the smallest size for all grid cells to have at least one neighboring cell), which is equivalent to a $55.5 \times 55.5 \mathrm{~km}$ grid at the Equator (Fig. 1).

Previous reports suggest an effect of orchard area on temporal and spatial disease progress known as the orchard edge effect, by which disease tends to spread into the orchard (Alves et al. 2020; Gasparoto et al. 2018; Gottwald et al. 2010; Leal et al. 2010; Shen

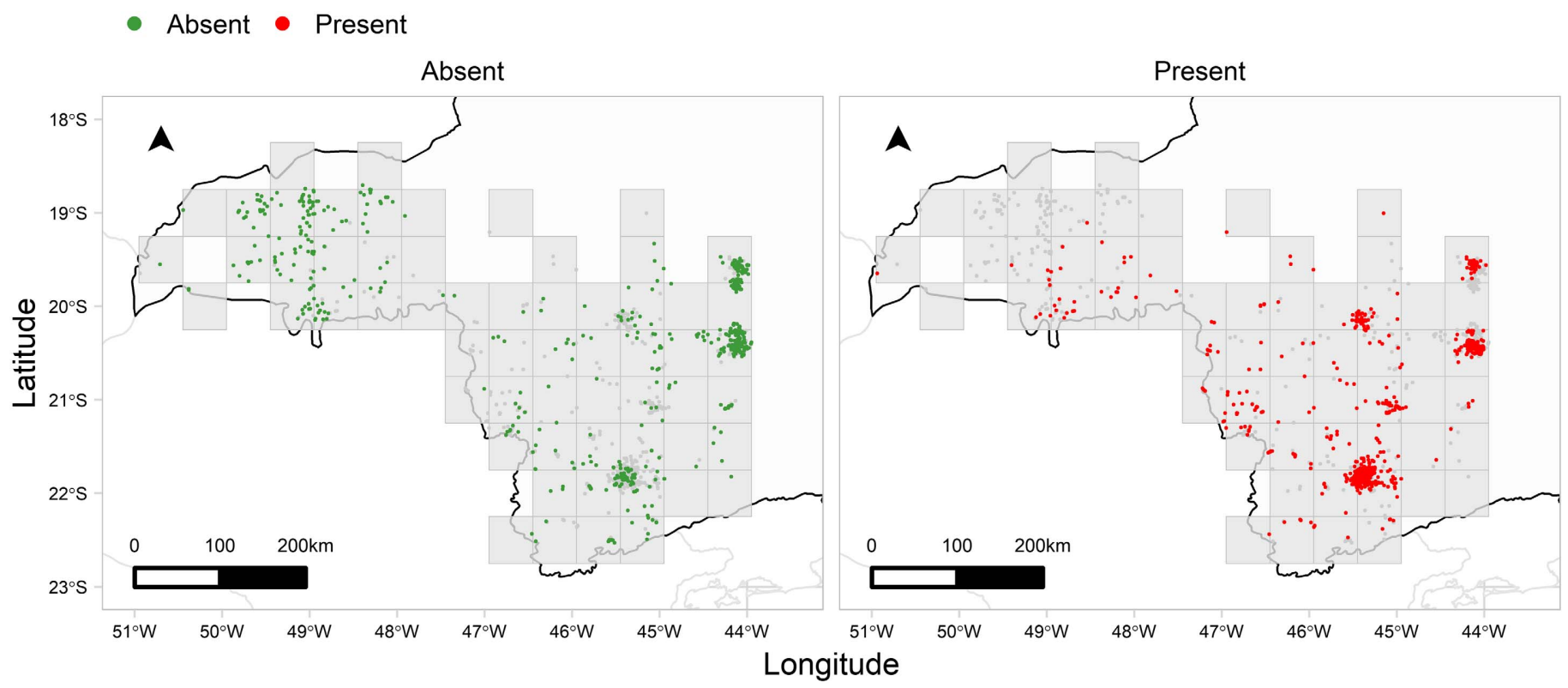

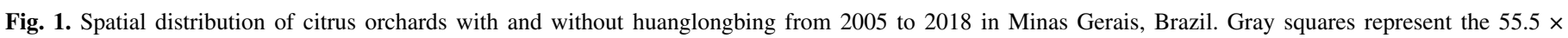
$55.5 \mathrm{~km}$ grid cells in which all data were based. 
et al. 2013). Consequently, the mean orchard areas were calculated by grid cells. Because there was a large range in orchard areas, with a few large orchards and many smaller orchards, area was logtransformed before spatial modeling. The number of mandarin and orange orchards in each grid cell was calculated, because recent work demonstrated that more mandarins are cultivated in the south region of MG compared with the west of the state, where sweet orange orchards predominate (Alves et al. 2020). The orchard type data were $\log$ transformed because of the presence of high values in some grid cells causing heterogeneity of variance. To avoid issues of log-transforming zero count data, we added 1 to all values of orchard type frequency.

Climate data. Climate data were obtained via the $\mathrm{R}$ package ( $\mathrm{R}$ Core Team 2021) nasapower (Sparks 2018). The nasapower package provides capability to download data from the NASA POWER (National Aeronautics and Space Administration Prediction of Worldwide Energy Resource, Washington, DC) database, which is freely available for download. Climate data (long-term monthly average and annual mean data for a 30-year period from January 1984 to December 2013) included temperature at $2 \mathrm{~m}$ $\left(T,{ }^{\circ} \mathrm{C}\right)$, precipitation (rainfall) $(P, \mathrm{~mm} / \mathrm{day})$, and wind speed at $10 \mathrm{~m}(W, \mathrm{~m} / \mathrm{s})$. The data obtained corresponded to the coordinates in the center of each $55.5 \times 55.5 \mathrm{~km}$ grid cell. To account for seasonal variations in the variables during the year, mean values of climatic variables during the rainy and dry seasons were calculated to obtain mean temperatures $\left(T_{\text {rainy }}\right.$ and $\left.T_{\text {dry }}\right)$, mean rainfall ( $P_{\text {rainy }}$ and $P_{\text {dry }}$ ), and mean wind speed ( $W_{\text {rainy }}$ and $W_{\text {dry }}$ ) during the rainy and dry seasons in MG. The averages for the rainy season were calculated from September to April (the end of winter to the beginning of autumn) (de Sá Júnior et al. 2012), and the averages for the dry season were calculated from May to August (the middle of autumn to the middle of winter) (de Sá Júnior et al. 2012).

Predictor variables. The candidate predictor variables were the log-transformed mean orchard area $(A)$, the log-transformed number of mandarin and orange orchards ( $N_{\text {mandarin }}$ and $\left.N_{\text {orange }}\right), T_{\text {rainy }}, T_{\text {dry }}$, $P_{\text {rainy }}, P_{\text {dry }}, W_{\text {rainy }}, W_{\text {dry }}$, mean annual wind speed ( $\left.W_{\text {annual }}\right)$, temperature $\left(T_{\text {annual }}\right)$, and rainfall $\left(P_{\text {annual }}\right)$. Subsequently, only a subset of these variables was used in the modeling procedure.

Additionally, a principal component analysis (PCA) of HLB prevalence in relation to the variables described previously was performed. This method was used to combine multiple covariates into a reduced number of uncorrelated principal components (PCs) to use as predictor variables. To account for different metrics across different variables, the PCA was performed based on the correlation matrix, in which the correlation of each variable with the PCs was expressed by a rotation with the Varimax method (Cendoya et al. 2020). The first three PCs were used as candidate predictors. The function 'principal()' from the psych package (Revelle 2020) was used to perform the PCA.

Modeling framework. A Bayesian hierarchical approach, similar to one used to analyze the spatial distribution of $X$. fastidiosa in Spain and Italy (Cendoya et al. 2020), was applied to the HLB data. An integrated nested Laplace approximations (INLA) computation method was used to obtain posterior probability distributions of the model's parameter and hyperparameters. The analysis was performed with the inla() function of the R package INLA (Rue et al. 2009).

The spatial model used was a reparameterization of the Besag-York-Mollié model (BYM model) (Besag et al. 1991), which is commonly used in disease mapping (Simpson et al. 2017). The objective is to model the observed HLB prevalence (incidence of HLB-affected orchards) $y_{i}$, in a grid cell $i$, where $i=1, \ldots, G$, with $G$ the number of grid cells. In our study $y_{i}$ is assumed to follow a binomial distribution, $y_{i} \sim \operatorname{Binomial}\left(n_{i}, \pi_{i}\right)$, where $n_{i}$ is the number of orchards in a grid cell and $\pi_{i}$ is the probability of an orchard being affected by HLB. The original BYM-model for the number of orchards in a grid cell is $\eta_{i}=\beta_{0}+X_{i} \beta_{m}+u_{i}+v_{i}$, where $\beta_{0}$ is the overall intercept, $\beta_{m}$ is the effect of the covariates (or predictors) ( $m=1, \ldots, N_{m}, N_{m}$ is the number of covariates), $u_{i}$ is a zero-mean Gaussian with a precision matrix representing the unstructured random effect, and $v_{i}$ is the random effects spatial component that accounts for the similarities of the neighboring grid cells (Besag 1974; Besag et al. 1991; Cendoya et al. 2020; Simpson et al. 2017). The reparametrized model (Equation 1) adds $v_{i}{ }^{*}$, which is the scaled spatially structured component (Simpson et al. 2017):

$$
\eta_{i}=\beta_{0}+X_{i} \beta_{m}+\frac{1}{\tau}\left(\sqrt{1-\phi} u_{i}+\sqrt{\phi} v_{i}^{*}\right)
$$

where $1 / \tau$ is the marginal precision contribution for $u_{i}$ and $v_{i}{ }^{*}$. The mixing parameter $\phi(0 \leq \phi \leq 1)$, is the fraction of the variance explained by the spatial structure, represented by $u_{i}$ and $v_{i}{ }^{*}$. Higher values of $\phi$ indicate high dependence on the spatial component. $X_{i}$ represents the vector of covariates. For further details about the reparameterized BYM model, the reader is referred to Simpson et al. (2017).

As described previously, the spatial grid used to aggregate HLB spatial data was defined as $0.5 \times 0.5$ decimal degrees. To obtain all grid cells with at least one neighboring cell, we converted grid coordinates to Universal Transverse Mercator coordinates. Two grid cells were considered to be neighbors if they were at a maximum distance of $100 \mathrm{~km}$. Coordinates were transformed to Universal Transverse Mercator via the spTransform() function in the $\mathrm{R}$ package $s p$ (Bivand et al. 2013).

The full model and respective priors for model parameter and hyperparameters are:

$$
\begin{gathered}
\eta_{i}=\beta_{0}+X_{i} \beta_{m}+\frac{1}{\tau}\left(\sqrt{1-\phi u_{i}}+\sqrt{\phi v_{i}^{*}}\right) ; \\
y_{i} \sim \operatorname{Binomial}\left(n_{i}, \pi_{i}\right), i=1, \ldots, G ; \\
\operatorname{logit}\left(\pi_{i}\right)=\beta_{0}+X_{i} \beta_{m}+\frac{1}{\tau}\left(\sqrt{1-\phi u_{i}}+\sqrt{\phi v_{i}^{*}}\right) ; \\
P\left(\beta_{0}\right) \propto 1 ; \\
\beta_{m} \sim N\left(\mu=0, \tau=10^{-3}\right), m=1, \ldots, N_{\beta} ; \\
\phi \sim \operatorname{PCprior}(0.5,2 / 3)
\end{gathered}
$$

where PCprior $(\cdot)$ defines the penalized complexity priors for the hyperparameters (Besag 1974; Besag et al. 1991; Cendoya et al. 2020; Simpson et al. 2017).

Model selection. To identify the best candidate models, a total of $2^{13}$ models would need to be tested (where 13 is the total number of covariates plus the spatial random effect), for a total of 8,192 models, which would require a lot of time and computational resources. To reduce the number of covariates and avoid multicollinearity, Pearson's correlations were performed between all candidate predictors. If the absolute correlation coefficient $|r|$ value was $>0.7$, one of the variables was removed from subsequent analysis. Remaining variables were used in the modeling procedure, in which $2^{k}$ models (where $k$ is the number of predictor variables including the spatial effect) were assessed via the Watanabe Akaike information criterion (WAIC; Watanabe 2010) and the logarithmic conditional predictive ordinate (LCPO; Pettit 1990). Models with lower WAIC and LCPO values were selected.

Data and code availability. All modeling procedures, downloading of climate data, and graphical work were performed in $\mathrm{R}$ version 4.0.2 ( $\mathrm{R}$ Core Team 2021); the code was fully annotated with $\mathrm{R}$ markdown (Xie et al. 2018) to enable reproducibility. The data tidying and exploratory analysis (including maps) presented in the study were conducted via procedures available in the tidyverse package (Wickham et al. 2019). Details for installation of the 
INLA package can be accessed at www.r-inla.org/download-install. All files (data and codes) used in the study were organized as a research compendium stored in the Open Science Framework and can be freely accessed for download at osf.io/nyvak.

\section{RESULTS}

CC model. The variables selected based on the $|r| \leq 0.7$ pairwise threshold were the log-transformed area $(A)$, the log-transformed number of mandarin and orange orchards $\left(N_{\text {mandarin }}\right.$ and $\left.N_{\text {orange }}\right)$, the mean temperature during the dry season $\left(T_{\mathrm{dry}}\right)$, the mean rainfall during the rainy season $\left(P_{\text {rainy }}\right)$, and the annual wind speed $\left(\mathrm{W}_{\text {annual }}\right)$. Distribution of values for these variables ranged from -0.51 to $7.24(A), 0$ to $5.69\left(N_{\text {mandarin }}\right), 0$ to $3.55\left(N_{\text {orange }}\right)$, $4.75 \mathrm{~mm} /$ day to $5.81 \mathrm{~mm} /$ day $\left(P_{\text {rainy }}\right), 15.26$ to $22.39^{\circ} \mathrm{C}\left(T_{\text {dry }}\right)$, and 1.72 to $3.56 \mathrm{~m} / \mathrm{s}$ ( $\left.W_{\text {annual }}\right)$. The spatial distribution maps of the orchard-related and climate variables are presented in Figure 2.

As six variables $\left(A, N_{\text {mandarin }}, N_{\text {orange }}, T_{\text {dry }}, P_{\text {rainy }}\right.$, and $\left.W_{\text {annual }}\right)$ and the spatial effect were selected, the number of models evaluated combining all variables was $2^{7}$, or a total of 128 models. The model with lowest WAIC (215.678) and LCPO (1.421) was the model that combined $P_{\text {rainy }}, T_{\text {dry }}, W_{\text {annual }}$, and random spatial effect. Besides the mean of the posterior distribution of the effect parameter for $P_{\text {rainy }}$ being positive, the $95 \%$ highest probability density (HPD, values ranging between $\mathrm{HPD}_{\text {lower }}$ and $\mathrm{HPD}_{\text {upper }}$ ) interval contained zero, which provided insufficient evidence of a positive effect of $P_{\text {rainy }}$ (Table 1). The mean of the posterior distribution for the effect of $T_{\text {dry }}$ was negative, and the HPD interval did not contain zero, providing evidence of a lower probability of HLB in regions with high temperatures during the dry season, and vice versa. On the other hand, we found evidence of a positive effect of wind speed on the distribution of HLB prevalence, because the posterior mean for the parameter of $W_{\text {annual }}$ was positive and the HPD interval did not contain zero (Table 1). The mean of the posterior distribution for the mixing parameter $\phi$ was 0.141 , indicating a partial influence of spatial effect on probability of HLB presence. The spatial distribution of the posterior mean and standard deviation of the spatial effect are presented (Fig. 3A and B, respectively). The posterior mean of the spatial effect ranged from -2.68 to 2.06 across the grid, and the posterior standard deviation ranged from 0.36 to 1.68 across the grid. Higher posterior mean values for the spatial effect indicate a higher probability of HLB presence.

The posterior distribution of HLB prevalence is given in terms of probability $\{0,1\}$, which may also be referred to as HLB risk. The spatial distribution of the posterior mean of HLB prevalence in MG based on the model with climate covariates and the spatial effect shows that the highest mean probability, 0.8650, was located in a region of high densities of citrus orchards in the eastern region (Fig. 3C and Fig. 1). In contrast, the lowest posterior mean probabilities, $<0.05$, were in peripheral grid cells to the northwest and south of the spatial grid, where most orchards were HLB-free (Fig. 3C). The posterior standard deviation of HLB prevalence ranged from 0.02 to 0.22 (Fig. 3D). Lower uncertainties were found on either low or high posterior means of HLB prevalence. Overall, there was a strong association between the estimated HLB risk and actual HLB prevalence (Fig. 3E; coefficient of determination $r^{2}=0.74$ ).

PC model. The first three principal components obtained in the PCA explained $81.1 \%$ of the total cumulative variation in the data (Table 2). The percentage of variance explained by the first, second, and third principal components was 30.7, 28.4, and $22.0 \%$,
A Precipitation in the rainy season

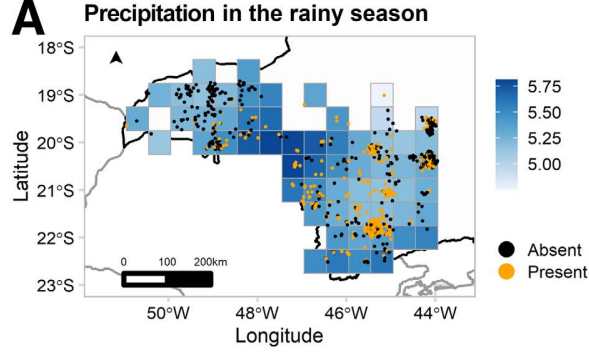

D Orange

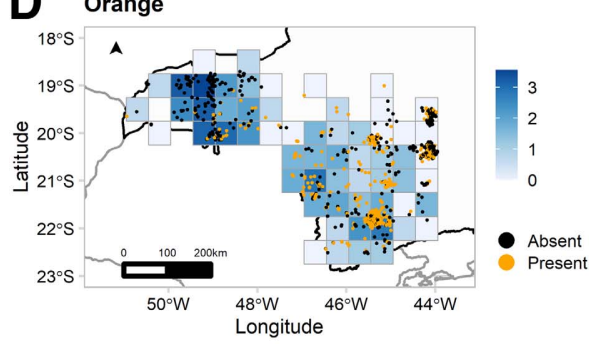

G PC1

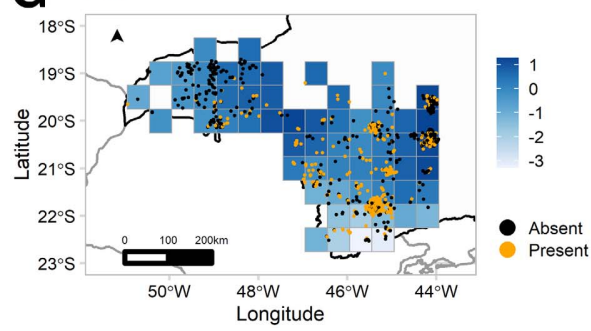

B

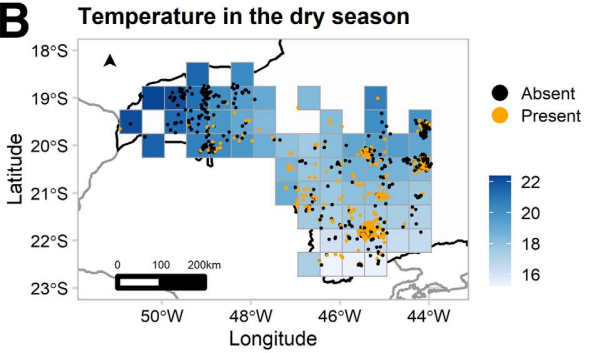

E

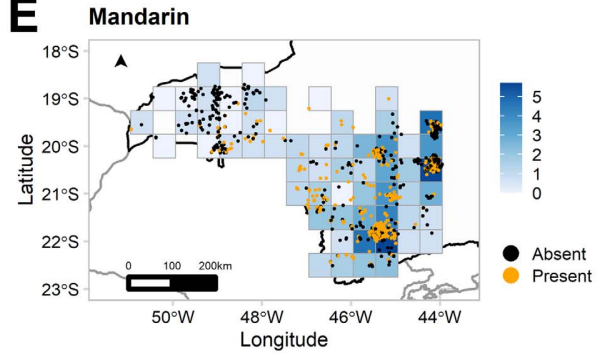

H

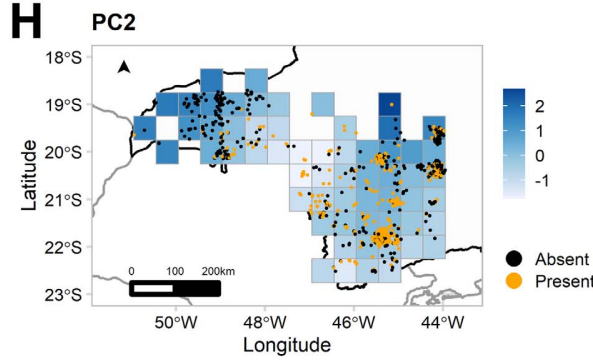

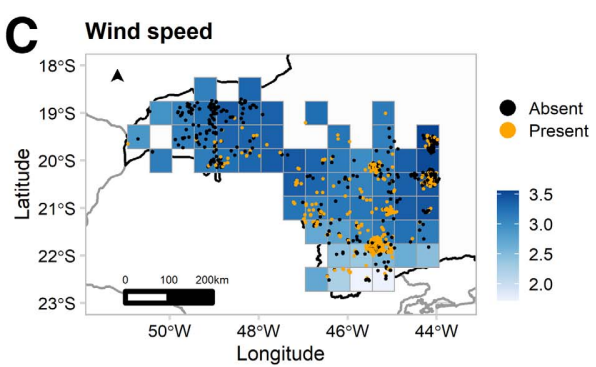

$\mathbf{F}$
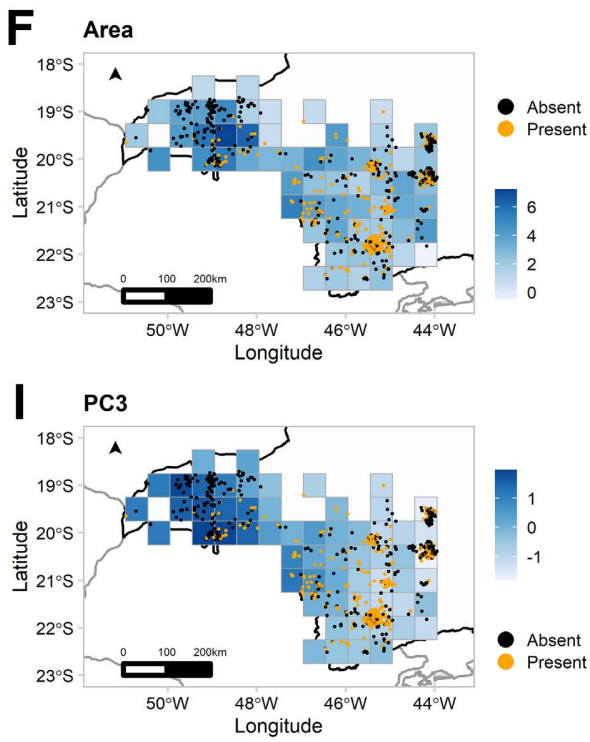

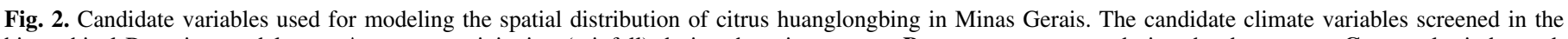

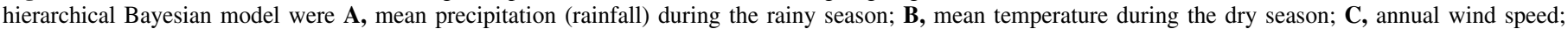

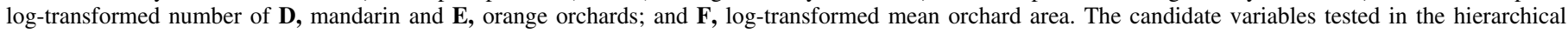

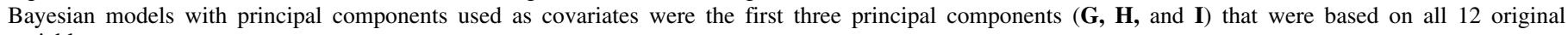
variables. 
respectively. Wind speed-related variables contributed the most to the first principal component $(\mathrm{PC} 1)$, with coefficients $>0.88$ ( $W_{\text {rainy }}$ contributed 0.974 to $\mathrm{PC} 1)$. For the second principal component (PC2), $P_{\text {annual }}$ contributed the most, with an estimated coefficient of -0.884 . For the third principal component (PC3), $T_{\text {rainy }}$ contributed the most and had an estimated coefficient of 0.660 (Table 2). Maps with the spatial distribution of each principal component were generated, but it was not possible to visualize a clear relationship between magnitude of the values and HLB presence (Fig. 2G, H, and I).

Using only the first three principal components and the spatial effect, we evaluated 16 models (equivalent to $2^{4}$ ). The model with the lowest WAIC (214.503) and a moderate LCPO value (6.35) was the model developed from PC1 and PC2 plus the spatial effect. The mean of the posterior distribution of the parameter for PC1 was positive, but the HPD interval contains zero, indicating insufficient evidence of an effect of PC1 (Table 3). However, the mean of the posterior distribution of the parameter for PC2 was negative and its HPD interval does not contain zero, indicating sufficient evidence of an effect of PC2 (Table 3). The mean of the posterior distribution of the mixing parameter $\phi$ was slightly higher than that of the model with climate covariates but also indicating a partial effect of the spatial effect on HLB presence (Table 3). The across-grid mean and standard deviation of the posterior distribution of the spatial effect are depicted in Figure 4A and B. Mean values ranged from -2.39 to 2.41 , and standard deviation ranged from 0.35 to 1.65 .

The posterior mean of HLB prevalence in MG ranged from 0.035 to 0.865 . The highest values are also in a region with a high density of orchards in the eastern region of the grid (Fig. 4C). Lower posterior probabilities were located in peripheral regions over western and southern MG. The posterior standard deviation of the probabilities ranged from 0.019 to 0.223 , and its spatial distribution was very similar to the model with climate covariates (Fig. 4D). Overall, there was a high correlation between the mean risk and actual HLB prevalence (Fig. 4E), in which the estimated coefficient of determination $\left(\mathrm{r}^{2}\right)$ was 0.75 , which indicates high model precision. In fact, the mean HLB risk predicted by both models presented here had a strong positive correlation (Pearson's $r=0.99)$.

\section{DISCUSSION}

Under two different modeling approaches (CC and PC), we used climate-driven models successfully to describe regional prevalence of HLB in MG, an important sweet orange and mandarin production region of Brazil. Among several climatic variables, we found evidence that the temperature during the dry season and annual wind speed were important in explaining the spatial distribution of HLB prevalence based on the CC model. In contrast, the

TABLE 1. Mean, median, standard deviation (SD), 95\% highest posterior density (HPD) interval, and mode of model parameters and hyperparameters of the best model with climate covariates for citrus huanglongbing prevalence distribution in Minas Gerais, Brazil

\begin{tabular}{|c|c|c|c|c|c|c|}
\hline Model & Mean & Median & SD & $\mathrm{HPD}_{\text {lower }}$ & $\mathrm{HPD}_{\text {upper }}$ & Mode \\
\hline \multicolumn{7}{|l|}{ Parameter $^{\mathrm{a}}$} \\
\hline$\beta_{0}$ & 1.244 & 1.245 & 8.309 & -15.241 & 17.618 & 1.270 \\
\hline$P_{\text {rainy }}$ & 1.264 & 1.264 & 1.198 & -1.102 & 3.625 & 1.263 \\
\hline$W_{\text {annual }} \mathrm{b}$ & 1.330 & 1.317 & 0.673 & 0.016 & 2.661 & 1.293 \\
\hline \multicolumn{7}{|c|}{ Hyperparameter } \\
\hline$\tau$ & 0.678 & 0.652 & 0.194 & 0.339 & 1.064 & 0.603 \\
\hline$\phi$ & 0.141 & 0.090 & 0.146 & $8.470 \times 10^{-6}$ & 0.451 & 0.010 \\
\hline
\end{tabular}

${ }^{\text {a }} \beta_{0}$, model intercept; $P_{\text {rainy }}$, precipitation (rainfall) in the rainy season (September to April); $T_{\text {dry }}$, temperature in the dry season (May to August); $W_{\text {annual }}$, annual wind speed; $\tau$, variance; $\phi$, the mixing parameter (spatial effect).

b $95 \%$ HPD interval excludes 0.
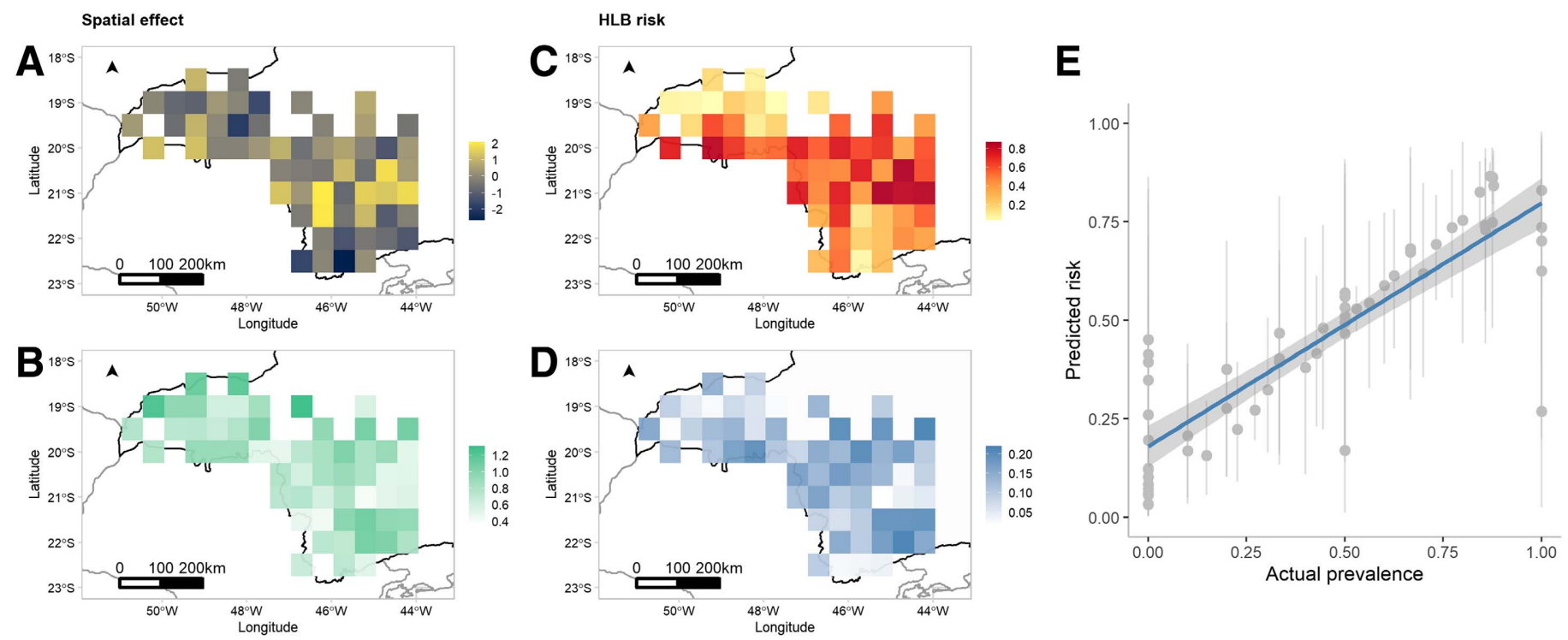

Fig. 3. Model with climate covariates and the spatial effect. A, Mean and $\mathbf{B}$, standard deviation of the posterior distribution of the spatial effect. C, Posterior mean and $\mathbf{D}$, standard deviation of the spatial distribution of HLB prevalence (or risk) in Minas Gerais with the climate covariate model with mean daily precipitation (rainfall) during the rainy season $\left(P_{\text {rainy }}\right)$, mean temperature during the dry season $\left(T_{d r y}\right)$, mean annual wind speed ( $\left.W_{\text {annual }}\right)$, and the spatial effect as covariates. E, Relationship between actual prevalence and the posterior mean (dots) and $95 \%$ highest posterior density (error bars) obtained with the climate covariate model. 
PC model suggested temperature was a key factor and included mean annual and rainy season rainfall as important variables. Both models suggested a partial spatial effect, although the CC model accounted for more spatial effect than that reported for the PC

TABLE 2. Loading of the first three principal components (PC1, PC2, and PC3) from the principal component analysis with climate and orchardrelated variables

\begin{tabular}{llcr}
\hline Variable $^{\mathrm{a}}$ & PC1 & PC2 & PC3 \\
\hline$A$ & 0.244 & -0.147 & 0.653 \\
$N_{\text {mandarin }}$ & & & -0.630 \\
$N_{\text {orange }}$ & -0.164 & & 0.649 \\
$P_{\text {annual }}$ & -0.279 & -0.884 & 0.238 \\
$P_{\text {dry }}$ & -0.739 & -0.566 & \\
$P_{\text {rainy }}$ & & -0.872 & 0.297 \\
$T_{\text {annual }}$ & 0.292 & 0.689 & 0.621 \\
$T_{\text {dry }}$ & 0.383 & 0.716 & 0.537 \\
$T_{\text {rainy }}$ & 0.237 & 0.666 & 0.660 \\
$W_{\text {annual }}$ & 0.974 & 0.154 & 0.115 \\
$W_{\text {dry }}$ & 0.883 & 0.219 & 0.364 \\
$W_{\text {rainy }}$ & 0.974 & 0.109 & \\
Variance $(\%)$ & 30.7 & 28.4 & 22.0 \\
Cumulative variance (\%) & 30.7 & 59.1 & 81.1 \\
\hline
\end{tabular}

${ }^{a} A$, orchard area $\left(\mathrm{m}^{2}\right) ; N_{\text {mandarin }}$, the log-transformed number of mandarin orchards; $N_{\text {orange, }}$ log-transformed number of orange orchards; $P_{\text {annual }}$, mean daily precipitation (rainfall) in the year; $P_{\mathrm{dry}}$, mean rainfall in the dry season (May to August); $P_{\text {rainy }}$, mean rainfall in the rainy season (September to April); $T_{\text {annual }}$, annual mean temperature; $T_{\text {dry }}$, mean temperature in the dry season; $T_{\text {rainy }}$, mean temperature in the rainy season; $W_{\text {annual }}$, annual windy speed; $W_{\mathrm{dry}}$, mean wind speed in the dry season; $W_{\text {rainy }}$, mean wind speed in the rainy season. model. Both models performed with high precision and provided comparable HLB predictions. Our findings are in consistent with the current knowledge of factors that affect HLB epidemics (Antolinez et al. 2021; Carmo-Sousa et al. 2020; Gasparoto et al. 2012; Martini et al. 2018). Models suggested an inverse relationship between temperatures during the dry (winter) period and HLB development and spread, whereas wind speed was directly associated with a greater likelihood of HLB development. With the PC model, increased mean annual and rainy season rainfall favored increased prevalence of HLB.

During May to August (autumn and winter), minimal to no-host flushing occurs, and as a result $D$. citri densities are lower, which has been suggested to reduce the risk of HLB (Gutierrez and Ponti 2013; Hall and Albrigo 2007; Lewis-Rosenblum et al. 2015; Teck et al. 2011). The temperature for the long-term, 30-year climate normals for the winter across the area of study ranged between 15 and $22^{\circ} \mathrm{C}$, more often $\geq 18^{\circ} \mathrm{C}$ (data not shown). Multiple studies have identified mild $\left(17\right.$ to $\left.22^{\circ} \mathrm{C}\right)$ to hot $\left(32\right.$ to $\left.50^{\circ} \mathrm{C}\right)$ temperatures as detrimental to ' $C a$. L. asiaticus' replication and survival (Gasparoto et al. 2012; Lopes et al. 2009; Razi et al. 2014). In agreement with those reports, the results of our study suggest that mean winter temperatures are inversely related to prevalence of HLB in MG, suggesting that in regions where temperatures are higher during the winter, the conditions may be detrimental to ' $\mathrm{Ca}$. L. asiaticus'. However, recently Lopes et al. (2017) reported temperatures $<15^{\circ} \mathrm{C}$ favored ' $\mathrm{Ca}$. L. asiaticus' titer in flushes on HLBsymptomatic trees, which had a lower frequency of occurrence across the region in our study. Also, the authors speculated that

TABLE 3. Mean, median, standard deviation (SD), 95\% highest posterior density (HPD) interval, and mode of model parameters and hyperparameters of the best model with principal components as covariates for citrus huanglongbing prevalence distribution in Minas Gerais, Brazil

\begin{tabular}{lrrrrr}
\hline Model & Mean & Median & SD & HPD $_{\text {lower }}$ & HPD $_{\text {upper }}$ \\
\hline Parameter $^{\mathrm{a}}$ & & & & & \\
$\quad \beta_{0}$ & -0.396 & -0.391 & 0.207 & -0.808 & 0.006 \\
PC1 & 0.036 & 0.034 & 0.212 & -0.379 & -0.383 \\
PC2 & -0.895 & -0.891 & 0.252 & -1.394 & 0.455 \\
Hyperparameter & & & & -0.405 \\
$\quad \tau$ & 0.623 & 0.602 & 0.169 & 0.324 & -0.882 \\
$\phi$ & 0.172 & 0.128 & 0.148 & 0.002 & 0.959 \\
\hline$\beta_{0}$ & & & 0.562 \\
\hline
\end{tabular}

a $\beta_{0}$, model intercept; PC1, first principal component; PC2, second principal component; $\tau$, variance; $\phi$, mixing parameter (spatial effect).

b $95 \%$ HPD interval excludes 0.
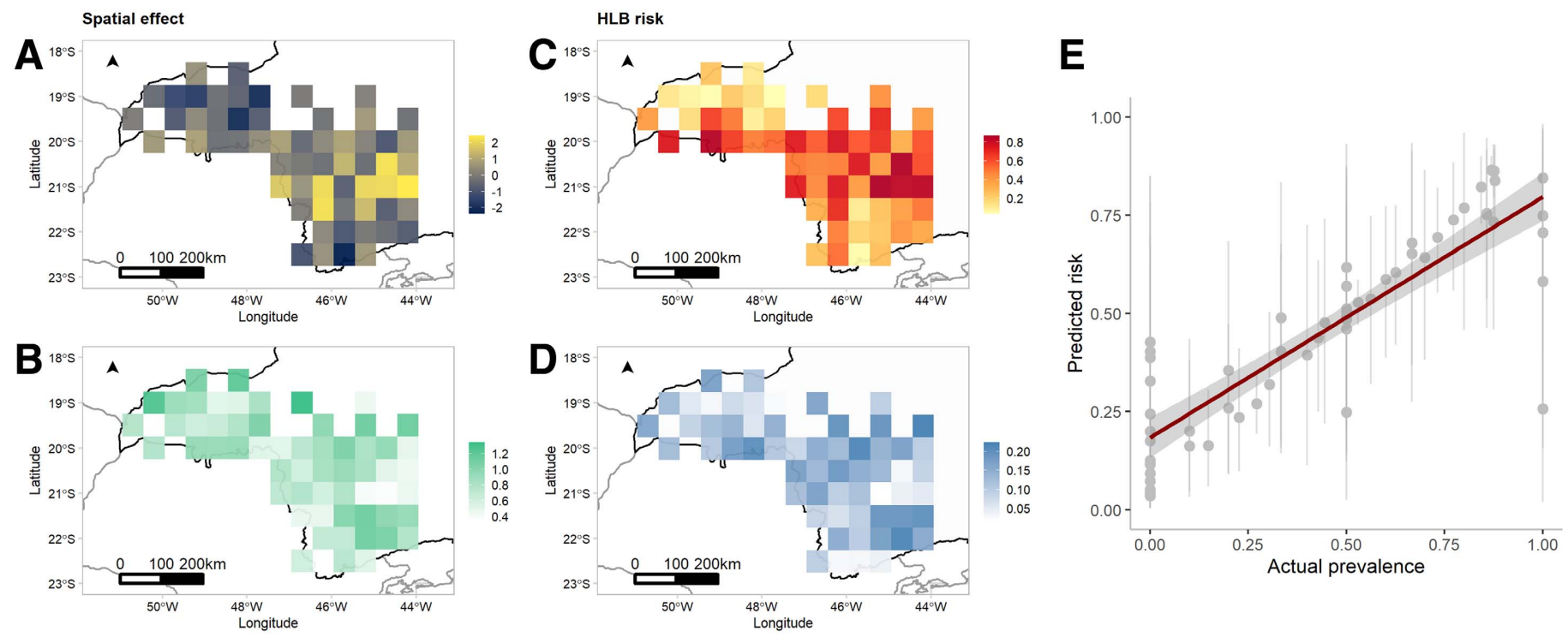

Fig. 4. Model with principal components and the spatial effect. A, Mean and B, standard deviation of the posterior distribution of the spatial effect. C, Posterior mean and $\mathbf{D}$, standard deviation of the spatial distribution of HLB prevalence (or risk) in Minas Gerais obtained with the model with the first and second principal components (PC1 and PC2) and the spatial effect as covariates. E, Relationship between actual prevalence and the posterior mean (dots) and 95\% highest posterior density (error bars) obtained with the principal components model. 
drier periods were associated with host trees experiencing water deficiency, reducing tissue availability for $D$. citri feeding and reproduction, which corroborates the negative dry season effect on HLB prevalence reported in our model.

Long- and short-distance dispersal of ' $\mathrm{Ca}$. L. asiaticus' depends on the dissemination of $D$. citri (Antolinez et al. 2021; Lewis-Rosenblum et al. 2015; Martini et al. 2018; Tomaseto et al. 2018). Tomaseto et al. (2018) reported that at $27.14^{\circ} \mathrm{C}$, approximately $50 \%$ of adult $D$. citri will initiate flight, although Martini et al. (2018) reported that a wider temperature range of 18 to $28^{\circ} \mathrm{C}$ lengthened flight duration and distance of D. citri. Recently, a decline in flight and no long-distance flight initiation was observed at temperatures $>32$ and $>43^{\circ} \mathrm{C}$, respectively (Antolinez et al. 2021). The findings are consistent with our results in relation to the inverse effect of temperature on HLB prevalence. The decrease in temperature may act as a stimulus that influences psyllid flight responses, which is an important response in regard to long-distance dispersal of ' $\mathrm{Ca}$. L. asiaticus'.

Adult psyllids are responsible for the spreading ' $\mathrm{Ca}$. L. asiaticus', whereas $D$. citri nymphs have greater acquisition efficiency, and support more rapid ' $\mathrm{Ca}$. L. asiaticus' replication (Ammar et al. 2016; George 2018; Gottwald 2010). The voluntary and involuntary movement of adult psyllids is associated with wind speed and direction (Carmo-Sousa et al. 2020). The mean annual wind speed in MG ranged from 6.19 to $12.8 \mathrm{~km} / \mathrm{h}$. The increase of wind speed in wind tunnels has been suggested to be directly associated with the involuntary movement of psyllids (Martini et al. 2018). The previous results support our thesis that an increase in wind speed is directly associated with HLB prevalence, which is due to a greater probability of psyllid movement and thus greater risk of HLB spread to and establishment in new areas. Determining optimal wind speed for flight initiation and termination may advance our understanding of $D$. citri movement and the concomitant spread of ' $C a$. L. asiaticus'. Our study did not include a wind direction component, although Antolinez et al. (2021) suggested that the inclusion of wind direction is critical in understanding the effect of wind on flight orientation. Therefore, we can only speculate about the contribution of wind direction to the partial spatial component of the CC model.

Although adult psyllids are capable of acquiring ' $\mathrm{Ca}$. L. asiaticus', the acquisition time needed is much longer, affecting temporal and spatial spread of the pathogen and its resulting prevalence (Ammar et al. 2016). The reduced contribution of the partial spatial effect may be a result of adult $D$. citri movement predominating during the spring and summer (i.e., the rainy season in MG), resulting in greater pathogen dissemination through vector dispersal (George 2018; Lewis-Rosenblum et al. 2015). However, a second explanation to the reduced spatial effect could be the long betweencell distance $(100 \mathrm{~km})$ used to create the neighborhood structure (spatial structure used as random effect) for modeling. If the grid cells had smaller dimensions and a neighborhood structure were constructed with a lower distance threshold $(<100 \mathrm{~km})$, which would imply a spatial dependence in smaller distances, the spatial effect might have had greater significance, because psyllids tend to disperse across distances $<100 \mathrm{~km}$.

Although the interpretation of effects due to individual variables during a modeling procedure when PCs are used as covariates is challenging (Cendoya et al. 2020), the PC model allows sufficient insight that greater rainfall due to both the annual and rainy season periods results in a greater risk of HLB. In the PCA model, warmer winters are associated with periods of reduced disease favorability, lowering the probability of HLB infection events, which is similar to the results of the CC model. But for the PC model, rainfall had more influence than temperature on HLB risk, which was due to the contributions of $\mathrm{PC} 2$.

Rainfall is associated with citrus host physiology and, in turn, with $D$. citri population dynamics. Greater populations of psyllid adults are associated with rainy season summer periods where more flush tissue is available (Gutierrez and Ponti 2013;
Lewis-Rosenblum et al. 2015; Narouei-Khandan et al. 2016; Shimwela et al. 2018; Tsai et al. 2002). In a multiple regression analysis, rainfall was associated with periods of host vegetative flushes, with a period of vegetative flushes in the rainy season and a second period of vegetative flushes in the dry season, and was significantly associated with favoring a higher titer of ' $\mathrm{Ca}$. L. asiaticus' in symptomatic flushes (Lopes et al. 2017). Our results corroborate these findings, providing evidence of a greater risk for HLB associated with higher annual and rainy season rainfall. Rainfall should be included as a regional risk assessment parameter and should improve the targeting and implementation of management strategies already in place.

Sampling and quantifying ' $\mathrm{Ca}$. L. asiaticus' titer in symptomatic trees (i.e., when flushes are present) or trapping psyllids in areas predicted to have a higher prevalence of HLB would confirm the assumptions of our model. Furthermore, oviposition and nymph development occur exclusively on young flushes (Hall et al. 2008). The risk for ' $C a$. L. asiaticus' acquisition by nymphs is greater and more rapid than that of adult $D$. citri, and as a result the probability for transmission to neighboring hosts increases as the $D$. citri nymphs mature (Ammar et al. 2016; George 2018; Gottwald 2010; Pelz-Stelinski et al. 2010).

We speculate that areas closer to HLB orchards are more likely to become infected than those farther away, suggesting a clustering or coalescence of HLB events, although the spatial effect was only partial. In this study, citrus orchards adjacent to SP would have a high probability of having trees with HLB, in contrast to areas in the northwest and south of MG, where there were lower posterior mean probabilities. Because ' $\mathrm{Ca}$. L. asiaticus' was first reported in SP, this result could be expected (Coletta-Filho et al. 2004; do Carmo Teixeira et al. 2005). Furthermore, Alves et al. (2020) indicated a greater spread of HLB in the areas bordering SP compared with the areas in central and south MG, although larger populations of ' $C a$. L. asiaticus'-positive psyllids were present in southwestern and northern SP, compared with the state border between MG and SP (Wulff et al. 2020).

The two models (CC and PC) we have presented could motivate targeted monitoring in regions with a higher HLB risk, focusing resources on orchards between poorly managed areas and newly planted or younger orchards. Furthermore, scouting in higher-risk regions for Citrus spp., in backyards, public gardens, pasture, and forests, may also contribute to mitigating HLB through eradicating and replacing ' $\mathrm{Ca}$. L. asiaticus'-infected trees (Bassanezi et al. 2013). Management strategies should consider climate effects when timing vector control intervention in HLB-favorable seasons and regions, in order to minimize dispersal of ' $\mathrm{Ca}$. L. asiaticus' between and within orchards, thereby enhancing area-wide management.

\section{LITERATURE CITED}

Alves, K. S., do Carmo, L. H. M., and Del Ponte, E. M. 2020. Spatiotemporal spread of huanglongbing in commercial citrus orchards of Minas Gerais, Brazil. Trop. Plant Pathol. 45:668-679.

Ammar, E.-D., Ramos, J. E., Hall, D. G., Dawson, W. O., and Shatters, R. G. 2016. Acquisition, replication and inoculation of Candidatus Liberibacter asiaticus following various acquisition periods on huanglongbinginfected citrus by nymphs and adults of the Asian citrus psyllid. PLoS One 11:e0159594.

Antolinez, C. A., Moyneur, T., Martini, X., and Rivera, M. J. 2021. High temperatures decrease the flight capacity of Diaphorina citri Kuwayama (Hemiptera: Liviidae). Insects 12:394.

Bassanezi, R. B., Busato, L. A., Filho, A. B., Amorim, L., and Gottwald, T. R. 2005. Preliminary spatial pattern analysis of Huanglongbing in São Paulo, Brazil. Int. Organ. Citrus Virol. Conf. Proc. 16:1957-2010.

Bassanezi, R. B., Lopes, S. A., de Miranda, M. P., Wulff, N. A., Volpe, H. X. L., and Ayres, A. J. 2020. Overview of citrus huanglongbing spread and management strategies in Brazil. Trop. Plant Pathol. 45:251-264.

Bassanezi, R. B., Montesino, L. H., Gimenes-Fernandes, N., Yamamoto, P. T., Gottwald, T. R., Amorim, L., et al. 2013. Efficacy of area-wide inoculum reduction and vector control on temporal progress of huanglongbing in young sweet orange plantings. Plant Dis. 97:789-796. 
Besag, J. 1974. Spatial interaction and the statistical analysis of lattice systems. J. R. Stat. Soc. Ser. B Methodol. 36:192-225.

Besag, J., York, J., and Mollié, A. 1991. Bayesian image restoration, with two applications in spatial statistics. Ann. Inst. Stat. Math. 43:1-20.

Bivand, R. S., Pebesma, E., and Gomez-Rubio, V. 2013. Applied Spatial Data Analysis With R. 2nd ed. Springer, New York.

Bové, J. M. 2006. Huanglongbing: A destructive, newly-emerging, century-old disease of citrus. J. Plant Pathol. 88:7-37.

Carmo-Sousa, M., Cortés, M. T. B., and Lopes, J. R. S. 2020. Understanding psyllid transmission of Candidatus Liberibacter as a basis for managing huanglongbing. Trop. Plant Pathol. 45:572-585.

Carvalho, S. A. D., Girardi, E. A., Mourão Filho, F. D. A. A., Ferrarezi, R. S., and Coletta Filho, H. D. 2019. Advances in citrus propagation in Brazil. Rev. Bras. Frutic. 41:e-422.

Cendoya, M., Martínez-Minaya, J., Dalmau, V., Ferrer, A., Saponari, M., Conesa, D., López-Quílez, A., and Vicent, A. 2020. Spatial Bayesian modeling applied to the surveys of Xylella fastidiosa in Alicante (Spain) and Apulia (Italy). Front. Plant Sci. 11:1204.

Coletta-Filho, H. D., Targon, M. L. P. N., Takita, M. A., De Negri, J. D., Pompeu, J., Machado, M. A., do Amaral, A. M., and Muller, G. W. 2004. First report of the causal agent of huanglongbing ("Candidatus Liberibacter asiaticus") in Brazil. Plant Dis. 88:1382.

Craig, A. P., Cunniffe, N. J., Parry, M., Laranjeira, F. F., and Gilligan, C. A. 2018. Grower and regulator conflict in management of the citrus disease Huanglongbing in Brazil: A modelling study. J. Appl. Ecol. 55:1956-1965.

de Sá Júnior, A., de Carvalho, L. G., da Silva, F. F., and de Carvalho Alves, M. 2012. Application of the Köppen classification for climatic zoning in the state of Minas Gerais, Brazil. Theor. Appl. Climatol. 108:1-7.

do Carmo Teixeira, D., Saillard, C., Eveillard, S., Danet, J. L., da Costa, P. I., Ayres, A. J., Bové, J. 2005. 'Candidatus Liberibacter americanus', associated with citrus huanglongbing (greening disease) in São Paulo State, Brazil. Int. J. Syst. Evol. Microbiol. 55:1857-1862.

Fundecitrus. 2019. Fundecitrus. https://www.fundecitrus.com.br/pdf/levantamentos/ levantamento-doencas-2019.pdf

Gasparoto, M. C. G., Coletta-Filho, H. D., Bassanezi, R. B., Lopes, S. A., Lourenço, S. A., and Amorim, L. 2012. Influence of temperature on infection and establishment of 'Candidatus Liberibacter americanus' and 'Candidatus Liberibacter asiaticus' in citrus plants. Plant Pathol. 61:658-664.

Gasparoto, M. C. G., Hau, B., Bassanezi, R. B., Rodrigues, J. C., and Amorim, L. 2018. Spatiotemporal dynamics of citrus huanglongbing spread: A case study. Plant Pathol. 67:1621-1628.

George, J. 2018. Prolonged phloem ingestion by Diaphorina citri nymphs compared to adults is correlated with increased acquisition of citrus greening pathogen. Sci. Rep. 8:10352.

Gottwald, T., Irey, M., Gast, T., Parnell, S., Taylor, E., and Hilf, M. 2010. Spatio-temporal analysis of an HLB epidemic in Florida and implications for spread. Proceedings, 17th Conference IOCV, 2010: Insect-Transmitted Procaryotes.

Gottwald, T. R. 2010. Current epidemiological understanding of citrus huanglongbing. Annu. Rev. Phytopathol. 48:119-139.

Gutierrez, A. P., and Ponti, L. 2013. Prospective analysis of the geographic distribution and relative abundance of Asian citrus psyllid (Hemiptera: Liviidae) and citrus greening disease in North America and the Mediterranean Basin. Fla. Entomol. 96:1375-1391.

Hall, D. G., and Albrigo, L. G. 2007. Estimating the relative abundance of flush shoots in citrus with implications on monitoring insects associated with flush. HortScience 42:364-368.

Hall, D. G., Hentz, M. G., and Adair, R. C., Jr. 2008. Population ecology and phenology of Diaphorina citri (Hemiptera: Psyllidae) in two Florida citrus groves. Environ. Entomol. 37:914-924.

Instituto Brasileiro de Geografia e Estatística (IBGE). 2018. Levantamento Sistemático da Produção Agrícola. https://www.ibge.gov.br/estatisticas/economicas/ agricultura-e-pecuaria/9201-levantamento-sistematico-da-producao-agricola.html?et= resultados

Jagoueix, S., Bové, J.-M., and Garnier, M. 1994. The phloem-limited bacterium of greening disease of citrus is a member of the $\alpha$ subdivision of the Proteobacteria. Int. J. Syst. Bacteriol. 44:379-386.

Leal, R. M., Barbosa, J. C., Costa, M. G., Belasque, J., Junior., Yamamoto, P. T., and Dragone, J. 2010. Distribuição espacial de Huanglongbing (Greening) em citros utilizando a geoestatística. Rev. Bras. Frutic. 32:808-818.

Lewis-Rosenblum, H., Martini, X., Tiwari, S., and Stelinski, L. L. 2015. Seasonal movement patterns and long-range dispersal of Asian citrus psyllid in Florida citrus. J. Econ. Entomol. 108:3-10.

Lopes, S. A., Bassanezi, R. B., Jr., and Yamamoto, P. T. 2008. Management of Citrus Huanglongbing in the State of São Paulo-Brazil.

Lopes, S. A., Bertolini, E., Frare, G. F., Martins, E. C., Wulff, N. A., Teixeira, D. C., Fernandes, N. G., and Cambra, M. 2009. Graft transmission efficiencies and multiplication of 'Candidatus Liberibacter americanus' and ' $\mathrm{Ca}$. Liberibacter asiaticus' in citrus plants. Phytopathology 99:301-306.
Lopes, S. A., Luiz, F. Q. B. F., Oliveira, H. T., Cifuentes-Arenas, J. C., and Raiol-Junior, L. L. 2017. Seasonal variation of 'Candidatus Liberibacter asiaticus' titers in new shoots of citrus in distinct environments. Plant Dis. 101:583-590.

Madden, L. V., Hughes, G., and van den Bosch, F. 2007. The Study of Plant Disease Epidemics. American Phytopathological Society, St. Paul, MN.

Martini, X., Rivera, M., Hoyte, A., Sétamou, M., and Stelinski, L. 2018. Effects of wind, temperature, and barometric pressure on Asian citrus psyllid (Hemiptera: Liviidae) flight behavior. J. Econ. Entomol. 111:8.

Narouei-Khandan, H. A., Halbert, S. E., Worner, S. P., and van Bruggen, A. H. C. 2016. Global climate suitability of citrus huanglongbing and its vector, the Asian citrus psyllid, using two correlative species distribution modeling approaches, with emphasis on the USA. Eur. J. Plant Pathol. 144:655-670.

Passos, O. S., da Silva Souza, J., Costa Bastos, D., Girardi, E. A., de Lima Gurgel, F., Bastos Garcia, M. V., de Oliveira, R. P., and dos Santos Soares Filho, W. 2018. Citrus Industry in Brazil With Emphasis on Tropical Areas in Citrus-Health Benefits and Production Technology. IntechOpen.

Pelz-Stelinski, K. S., Brlansky, R. H., Ebert, T. A., and Rogers, M. E. 2010. Transmission parameters for Candidatus Liberibacter asiaticus by Asian citrus psyllid (Hemiptera: Psyllidae). J. Econ. Entomol. 103:1531-1541.

Pettit, L. I. 1990. The conditional predictive ordinate for the normal distribution. J. R. Stat. Soc. Ser. B Methodol. 52:175-184.

R Core Team. 2021. R: A Language and Environment for Statistical Computing. R Foundation for Statistical Computing, Vienna, Austria.

Razi, M. F., Keremane, M. L., Ramadugu, C., Roose, M., Khan, I. A., and Lee, R. F. 2014. Detection of citrus huanglongbing-associated 'Candidatus Liberibacter asiaticus' in citrus and Diaphorina citri in Pakistan, seasonal variability, and implications for disease management. Phytopathology 104: 257-268.

Revelle, W. 2020. psych: Procedures for Psychological, Psychometric, and Personality Research. Northwestern University, Evanston, IL.

Rue, H., Martino, S., and Chopin, N. 2009. Approximate Bayesian inference for latent Gaussian models by using integrated nested Laplace approximations. J. R. Stat. Soc. Ser. B. Stat. Methodol. 71:319-392.

Shen, W., Halbert, S. E., Dickstein, E., Manjunath, K. L., Shimwela, M. M., and van Bruggen, A. H. C. 2013. Occurrence and in-grove distribution of citrus huanglongbing in north central Florida. J. Plant Pathol. 95:361-371.

Shimwela, M. M., Schubert, T. S., Albritton, M., Halbert, S. E., Jones, D. J., Sun, X., Roberts, P. D., Singer, B. H., Lee, W. S., Jones, J. B., Ploetz, R. C., and van Bruggen, A. H. C. 2018. Regional spatial-temporal spread of citrus huanglongbing is affected by rain in Florida. Phytopathology 108:1420-1428.

Simpson, D., Rue, H., Riebler, A., Martins, T. G., and Sørbye, S. H. 2017. Penalising model component complexity: A principled, practical approach to constructing priors. Stat. Sci. 32:1-28.

Sparks, A. H. 2018. nasapower: A NASA POWER global meteorology, surface solar energy and climatology data client for R. J. Open Source Softw. 3:1035.

Teck, S. L. C., Fatimah, A., Beattie, A., Heng, R. K. J., and King, W. S. 2011. Seasonal population dynamics of the Asian citrus psyllid, Diaphorina citri Kuwayama in Sarawak. Am. J. Agric. Biol. Sci. 6:527-535.

Tomaseto, A. F., Miranda, M. P., Moral, R. A., de Lara, I. A. R., Fereres, A., and Lopes, J. R. S. 2018. Environmental conditions for Diaphorina citri Kuwayama (Hemiptera: Liviidae) take-off. J. Appl. Entomol. 142: 104-113

Tsai, J. H., Wang, J.-J., and Liu, Y.-H. 2002. Seasonal abundance of the Asian citrus psyllid, Diaphorina citri (Homoptera: Psyllidae) in southern Florida. Fla. Entomol. 85:446-452.

Van Vuuren, S. P., and Da Graça, J. V. 1993. Variable transmission of African greening to sweet orange. Pages 264-268 in Proceedings of the 12th Conference of the International Organization of Citrus Virologists. University of California, Riverside.

Watanabe, S. 2010. Asymptotic equivalence of Bayes cross validation and widely applicable information criterion in singular learning theory. J. Mach. Learn. Res. 11:3571-3594.

Wickham, H., Averick, M., Bryan, J., Chang, W., McGowan, L. D., François, R., Grolemund, G., Hayes, A., Henry, L., Hester, J., Kuhn, M., Pedersen, T. L., Miller, E., Bache, S. M., Müller, K., Ooms, J., Robinson, D., Seidel, D. P., Spinu, V., Takahashi, K., Vaughan, D., Wilke, C., Woo, K., and Yutani, H. 2019. Welcome to the tidyverse. J. Open Source Softw. 4:1686.

Wulff, N. A., Daniel, B., Sassi, R. S., Moreira, A. S., Bassanezi, R. B., Sala, I., Coletti, D. A. B., and Rodrigues, J. C. 2020. Incidence of Diaphorina citri carrying Candidatus Liberibacter asiaticus in Brazil's citrus belt. Insects 11:672.

Xie, Y., Allaire, J. J., and Grolemund, G. 2018. R Markdown: The Definitive Guide. Chapman and Hall/CRC, Boca Raton, FL. 